\title{
DHA-enriched supplement ameliorates cancer- associated systemic inflammatory response via resolvin D1 production: a single institutional study
}

Yasuhiko Mohri', Koji Tanaka ${ }^{2}$, Hiroki Imaoka ${ }^{1}$, Chikao Miki ${ }^{2}$, Hiroyuki Fujikawa ${ }^{1}$, Tadanobu Shimura ${ }^{1}$, Yuji Toiyama ${ }^{1}$, Toshimitsu Araki ${ }^{1}$, Yasuhiro Inoue ${ }^{1}$ and Masato Kusunoki ${ }^{1}$

${ }^{1}$ Department of Gastrointestinal and Pediatric Surgery, Mie University Graduate School of medicine, Japan

${ }^{2}$ Department of Surgery, Iga City General Hospital, Iga, Mie, Japan

\begin{abstract}
Colorectal cancer patients with systemic inflammation as evidenced by elevated C-reactive protein (CRP) have been shown to have significantly worse prognosis. Recent reports demonstrated that resolvin D1, a novel lipid mediator generated from dochosahexaenoic acid (DHA), activates factors that reduce inflammation. This study was designed to investigate not only the relationship between CRP and resolvins (resolvin D1 and resolvin E1) but also the effect of DHA on CRP in colorectal cancer patients with systemic inflammatory response.

Relationship between serum levels of CRP and resolvins in colorectal cancer was investigated by using commercially available assay kits. The effect of DHA and/ or eicosapentaenoic acid (EPA) on cell proliferation was also evaluated using colorectal carcinoma cell lines. The clinical study was conducted to check whether supplementation of $2.2 \mathrm{~g}$ /day of DHA-enriched fish oil for one week ameliorates the systemic inflammatory response in patients with advanced or recurrent colorectal cancer.

The serum levels of resolvin D1 in colorectal patients with CRP $\geqq 0.5 \mathrm{mg} / \mathrm{dL}$ were significantly lower than those in patients without. In the in vitro study, DHA was more efficient than EPA in suppressing cell proliferation. Ten patients with colorectal cancer in chemotherapy were enrolled in clinical supplementing study. Eight of the ten patients showed decreased levels of CRP after the one week supplementation compared with the levels before supplementation. Also, eight of the ten patients showed increased levels of resolvin D1 after the supplementation compared with the levels before supplementation.

Taken together, these data suggest that the dietary DHA-enriched supplement ameliorates cancer-associated systemic inflammatory response at least in part via upregulation of resolvin D1.
\end{abstract}

\section{Introduction}

Colorectal cancer is currently one of the most prevalent causes of cancer death [1]. Although various chemotherapy regimens and biological drugs have been developed, the outcome of colorectal cancer is not sufficient. Excessive inflammation has emerged as a critical component in many prevalent human diseases including cancer [2,3]. There is increasing evidence that the elevated C-reactive protein (CRP) in various solid tumors including colorectal cancer is an independent prognostic factor [4-6]. Previous reports demonstrated that interleukin-6 (IL-6) in tumor and serum in patients with colorectal cancer plays a key role in systemic inflammatory response such as elevated CRP [7-9]. However, it is still unclear whether this cancerassociated inflammation is reversible or not.

Omega-3 fatty acids (omega-3 FAs) mostly promote antiinflammatory activities [10]. The therapeutic benefit of marine-based foods on cancer has been proven by several experimental studies, which have been performed focusing on omega-3 FAs [11-15]. Resolvin familiy, novel enzymatically oxygenated lipid mediators derived from eicosapentaenoic acid (EPA) or docosahexaenoic acid (DHA), were recently identified in resolving exudates [16]. Increasing evidence in basic research indicates that resolvin family possesses potent anti- inflammatory and immunoregulatory actions [16-19]. However, there are few clinical data about the effects of resolvin family on resolution of systemic inflammation, such as elevated CRP, in cancer patients.

In this study, first, we examined the relationship between systemic inflammation as evidenced by elevated CRP and resolvins. Next, we investigated the cytotoxic effect of DHA and/or EPA on human colon adenocarcinoma cells. Third, we determined whether supplementation of DHA-enriched supplement for one week in patients with advanced or recurrent colorectal cancer receiving chemotherapy alters inflammation markers, such as CRP.

Correspondence to: Yasuhiko Mohri, MD, PhD, FACS. Department of Gastrointestinal and Pediatric Surgery, Mie University Graduate School of Medicine, 2-174 Edobashi, Tsu, Mie 514-8507, Japan, Tel: +81-59-231-5294; Fax: +81-59-232-6968; E-mail: ya-mohri@clin.medic.mie-u.ac.jp

Key words: colorectal cancer, systemic inflammatory response, C-reactive protein, docosahexaenoic acid, and resolvin D1

Received: October 24, 2016; Accepted: November 14, 2016; Published: November 16, 2016 


\section{Materials and methods}

\section{Correlation between serum CRP level and resolving D1 and E1}

To determine the correlation between serum CRP level and resolvins (resolve D1 and resolving E1), we collected the blood samples from 35 patients who diagnosed a colorectal cancer and 10 healthy volunteers. The serum levels of CRP were measured with a turbidimetric immunoassay using an N-Assay TIA CRP-S kit (Nittobo Medical, Tokyo). The serum levels of resolvin D1 and E1 were measured using commercially available ELISA kits (resolvin E1; MyBiosource, Inc, San Diego, CA, resolvin D1; CAYMAN CHEMICAL, Michigan, USA).

\section{Cell viability assay for DHA and EPA}

Human colorectal cancer cell lines HT29 and LoVo were obtained from the Cell Resource Center of Biomedical Research, Institute of Development, Aging and Cancer (Tohoku University, Sendai, Japan). These cell lines were maintained in RPMI-1640 medium supplemented with $10 \%$ fetal bovine serum, $100 \mathrm{IU} / \mathrm{ml}$ penicillin and $100 \mu \mathrm{g} / \mathrm{ml}$ streptomycin at $37^{\circ} \mathrm{C}$ in a $5 \%$ humidified $\mathrm{CO}_{2}$ atmosphere. DHA and EPA were obtained from Sigma-Aldrich Inc. (Buchs, Switzerland), and were diluted in ethanol and stored at $10 \mathrm{mg} / \mathrm{ml}$ at $-80^{\circ} \mathrm{C}$.

The cytotoxicity was evaluated using a WST-8 [2-(2-methoxy4-nitrophenyl)-3-(4-nitrophenyl)-5-(2,4-disulfophenyl)-2Htetrazolium, monosodium salt] colorimetric assay. WST-8 is a modification of the MTT assay, which was applied to estimation of cellular viability using a commercially available kit (cell counting kit, Dojindo Laboratories, Japan). HT29 and Lovo cells (5,000 cells/well) were seeded into 96-well cell plates (Becton Dickson Labware, NJ, USA) in $100 \mu \mathrm{l}$ of culture medium for 24 hours prior to fatty acid (FA) exposure, and then treated with various concentrations of DHA and/or EHA for 48 hours. After FA exposure for the indicated concentrations and times, the medium was discarded and replaced with $90 \mu \mathrm{l}$ of fresh medium. Next, $10 \mu \mathrm{l}$ of WST-8 reagent solution (Cell Counting Kit; Dojindo Laboratories, Kumamoto, Japan) was added and incubated for 4 hours at $37^{\circ} \mathrm{C}$ in an incubator. Cell viability was determined colorimetrically by the optical density (OD) at a wavelength of 450 $\mathrm{nm}$, as measured using a microplate reader. Cytotoxicity was evaluated using the Cell Counting Kit according to manufacturer's instructions. The supernatants obtained from Lovo cell line culture were harvested at $24,48,72$ hours and stored at $-80^{\circ} \mathrm{C}$ until assayed. The supernatant concentration of IL- 6 was measured using commercially available ELISA kit for IL-6 (R\&D systems, Minneapolis, USA).

\section{Supplementation of DHA-enriched supplement and changes of CRP level}

Patients with colorectal cancer treated in the Mie University Hospital, Mie, Japan were participated. The eligibility criteria were: age $\geqq 20$ years; histopathological diagnosis of colorectal carcinoma; CRP $\geqq$ $0.5 \mathrm{mg} / \mathrm{dL}$; and chemotherapy treatment indication. Not included were those in palliative care; taking statin or anti-inflammatory drugs; with allergy to fish and derivatives; without oral intake conditions; previously subjected to chemotherapy; or patients with autoimmune diseases and; those who had used supplements containing fish oil or omega-3 FAs during the three months prior to study initiation. Individual energy requirements for patients were estimated by Harris-Benedict equation [20]. Based on these requirements, patients were advised to follow a diet based on standardized menus of 1600, 1800, or $2000 \mathrm{kcal}$. No extra calories were provided, and patients were given isocaloric diets.
The fish oil supplement was offered in the form of gelatinous micro-capsules with $20 \mathrm{mg} /$ capsule (Toyo capsule Inc, Japan). Each capsule contained $11 \mathrm{mg}$ of $\mathrm{n}-3$ polyunsaturated FAs (7.6 mg of DHA and $0.84 \mathrm{mg}$ of EPA). The participants were instructed to ingest 200 micro-capsules/day of fish oil (2.2 g/day), in addition to their habitual dietary intake, for one week. They were instructed to ingest the capsules in a dose-fractionated form (100 capsules $\times 2$ times), about 20-30 min before two main meals and accompanied by liquid. In addition, they were instructed to record capsule intake in a specific form provided. Blood samples $(9 \mathrm{ml})$ were collected after approximately $8 \mathrm{~h}$ fasting at two times: on the day prior to supplementation and one week later. The material was collected in separating gel tubes for the determination of serum CRP and resolvin D1. The study protocol was approved by the Human Research and Ethics Committee of the institution and was in accordance with the Declaration of Helsinki. All participants agreed to participate by signing a consent form.

\section{Statistical analysis}

The Mann-Whitney $U$ test was used for comparisons among unpaired groups. The Wilcoxon signed rank test was used for paired analysis. $\mathrm{P}$ values of less than 0.05 were considered statistically significant.

\section{Results}

\section{Correlation between serum CRP level and resolvin D1/E1}

The backgrounds are shown in Table 1 . The levels of CRP in all healthy volunteers were less than $0.5 \mathrm{mg} / \mathrm{dL}$. Twenty-eight percent $(n=10)$ of colorectal patients had the CRP level at or greater than 0.5 $\mathrm{mg} / \mathrm{dL}$. When the patients were divided into three groups based on the levels of CRP, i.e., CRP $<0.5 \mathrm{mg} / \mathrm{dl}, 0.5 \leqq \mathrm{CRP}<1.0 \mathrm{mg} / \mathrm{dl}$, CRP $\geqq 1.0 \mathrm{mg} / \mathrm{dl}$, the median values of resolving E1 in healthy volunteers, patients with CRP $<0.5 \mathrm{mg} / \mathrm{dL}$, patients with $0.5 \leqq \mathrm{CRP}<1.0 \mathrm{mg} / \mathrm{dL}$, and patients with CRP $\geqq 1.0 \mathrm{mg} / \mathrm{dL}$ were $1,802,1,902,2,688,1,174$ $\mu \mathrm{g} / \mathrm{ml}$, respectively. No significant differences were observed between each group (Figure 1a). The median values of resolving D1 in healthy volunteers, patients with $\mathrm{CRP}<0.5 \mathrm{mg} / \mathrm{dL}$, patients with $0.5 \leqq \mathrm{CRP}$ $<1.0 \mathrm{mg} / \mathrm{dL}$, and patients with CRP $\geqq 1.0 \mathrm{mg} / \mathrm{dL}$ were $8,241,9,193$, $3,107,2,599 \mu \mathrm{g} / \mathrm{ml}$, respectively. The levels of resolvin D1 in patients with $0.5 \leqq \mathrm{CRP}<1.0 \mathrm{mg} / \mathrm{dL}$ and patients with CRP $\geqq 1.0 \mathrm{mg} / \mathrm{dL}$ were significantly lower than healthy volunteers (Figure $1 \mathrm{~b}$ ). However, No significant difference was observed between healthy volunteers and patents with $\mathrm{CRP}<0.5 \mathrm{mg} / \mathrm{dL}$.

Table 1. Demographic and clinical features of patients from serum samples were collected to analyze the relationship between C-reactive protein and resolvins.

\begin{tabular}{|l|c|c|}
\hline & Healthy volunteer & Colorectal patients \\
\hline Age, median (range) & $\mathrm{N}=10$ & $\mathrm{~N}=35$ \\
\hline Male (\%) & $60(44-72)$ & $66(42-81)$ \\
\hline C-reactive protein (mg/dL), median & $7(70)$ & $22(63 \%)$ \\
(range) & $0.085(0.01-0.2)$ & $0.14(0.01-16.42)$ \\
\hline CRP (\%) & & \\
$<0.5$ & 10 & $25(72 \%)$ \\
$0.5-1.0$ & & $6(17 \%)$ \\
$>1.0$ & & $4(11 \%)$ \\
\hline Stage (\%) & & $6(17 \%)$ \\
I & & $15(43 \%)$ \\
II & & $3(9 \%)$ \\
III & & $11(31 \%)$ \\
IV & & \\
\hline
\end{tabular}



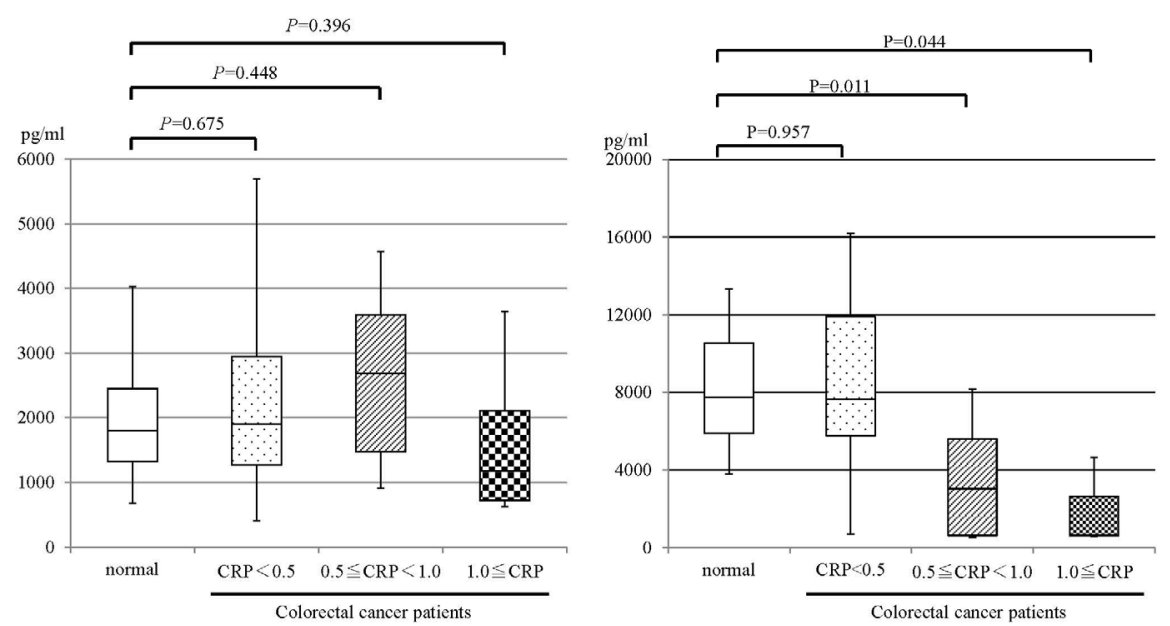

Figure 1. Correlation between the levels of CRP and resolvins in healthy volunteer and colorectal patients. a: resolvin E1, b resolvin D1. normal, healthy volunteer; CRP $<0.5$, colorectal patients with $\mathrm{CRP}<0.5 \mathrm{mg} / \mathrm{dl} ; 0.5 \leqq \mathrm{CRP}<1.0$, colorectal patients with the $0.5 \leqq \mathrm{CRP}<1.0 \mathrm{mg} / \mathrm{dl} ; 1.0 \leqq \mathrm{CRP}$, colorectal patients with $\mathrm{CRP} \leqq 1.0 \mathrm{mg} / \mathrm{dl}$.

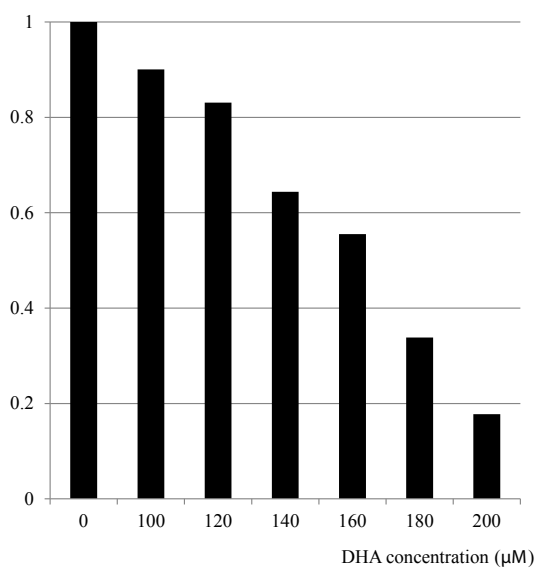

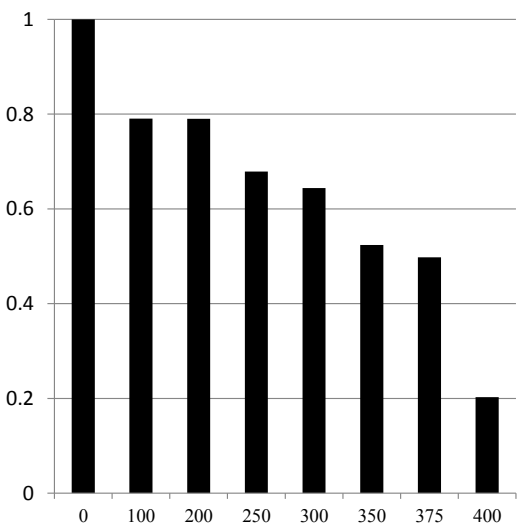

EPA concentration $(\mu \mathrm{M})$

Figure 2. Effect of omega-3 fatty acids (DHA and EPA) supplementation on cell proliferation of HT 29 colorectal cancer cell line.aDHA, bEPA.

\section{Growth inhibition of colorectal cancer cells by DHA and EPA}

To elucidate the impact of DHA or EPA on cell growth inhibition, we evaluated the dose-dependent cell viabilities after exposure to each FA (DHA or EPA) individually. The cytotoxic effects of DHA or EPA on HT29 cells were assessed after 48 hour exposure, followed by the WST-8 colorimetric assay. Growth inhibitory effects were observed for treatment with either DHA or EPA alone in dose- and timedependent manners (Figure 2 and our unpublished data). Moreover, the inhibitory effect of DHA on the cell growth was less clear at lower concentrations compared with that of EPA (Figure $2 a$ and $b$ ). To elucidate the optimal combination ratio of DHA and EPA for cell growth inhibition, we next evaluated the cell viabilities after exposure under the various combination ratios of EPA and DHA, individually. The most pronounced cytotoxicity was observed for $200 \mu \mathrm{M}$ DHA (Figure 3). Regarding the clinical use of DHA/EPA combinations, these results suggest that rich concentration of DHA is effective to inhibit cancer cell growth.

\section{Inhibition of producing IL-6 from Lovo cells by DHA}

As the IL-6 production was observed only in Lovo cells, we chose

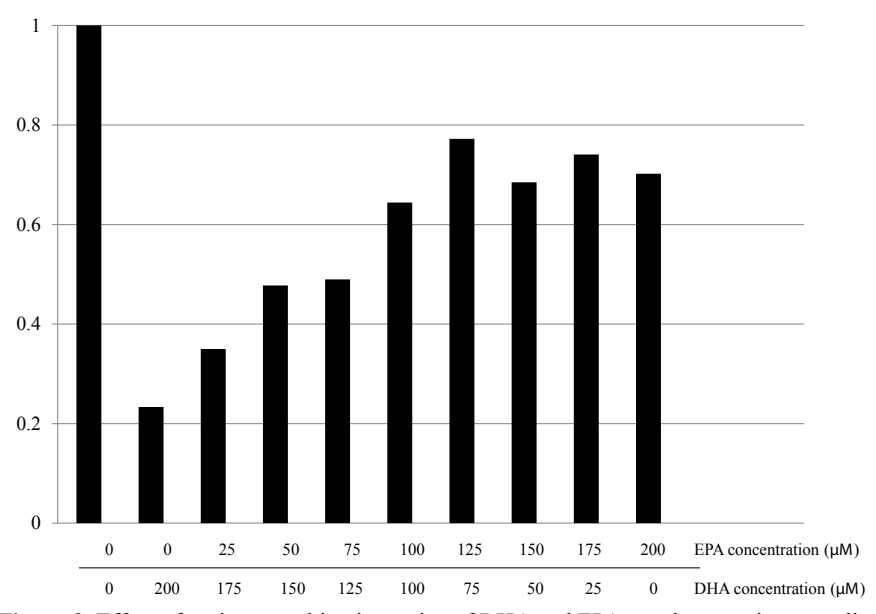

Figure 3. Effect of various combination ratios of DHA and EPA supplementation on cell proliferation of HT 29 colorectal cancer cell line.

the Lovo cells in this examination. In the culture supernatant of the control (no treatment) cells, IL-6 concentration was time-dependently increased. The IL- 6 production in Lovo cells treated with DHA after 72 
hour incubation was significantly more inhibited than that in Lovo cell without DHA (Figure 4).

\section{Supplementation of DHA-enriched omega-3 fatty acid}

We examined the effect of DHA-enriched supplement on serum CRP level in colorectal patients with elevated CRP. Ten patients were enrolled in this study. Baseline characteristics of the patients were shown in Table 2. All patients were able to take the supplement according to the protocol. Although one patient had experienced loose stool, no severe adverse events were observed. There were eight patients whose CRP levels were reduced after one week of supplementation compared with those before supplementation (Figure 5a). Among them, 5 patients had the CRP $<0.5 \mathrm{mg} / \mathrm{dl}$ after supplementation (Figure $5 \mathrm{a}$ ). Although the median reduction rate, which was calculated from ((CRP before supplementation - CRP after one week supplementation)/ CRP before supplementation) $) \times 100$, was $64.3 \%$, the significant

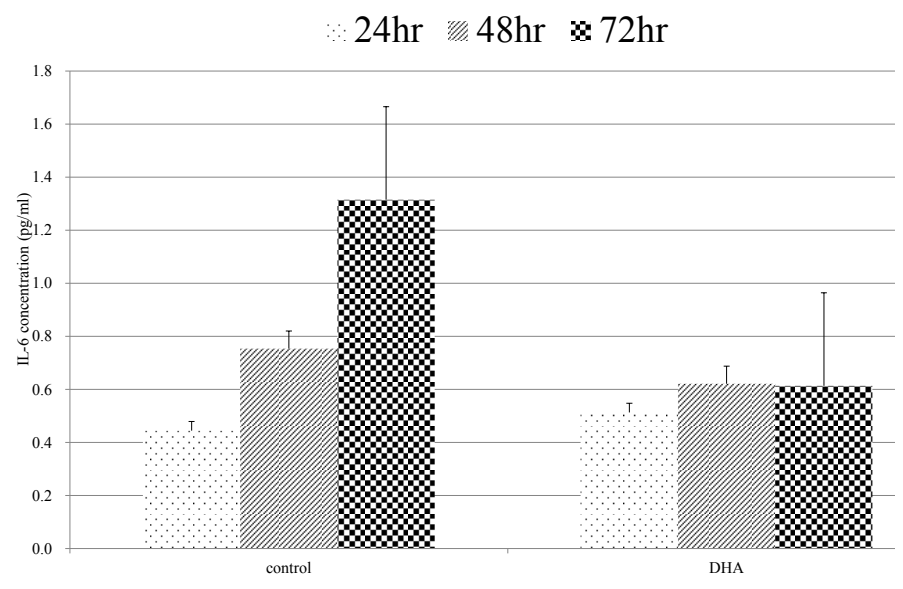

Figure 4. Quantification of IL-6 concentration. Cells were treated with $200 \mu \mathrm{M} / \mathrm{L}$ DHA for 72 hours. IL- 6 concentrations of supernatant were measured at 24,48 , and 72 hours.

a

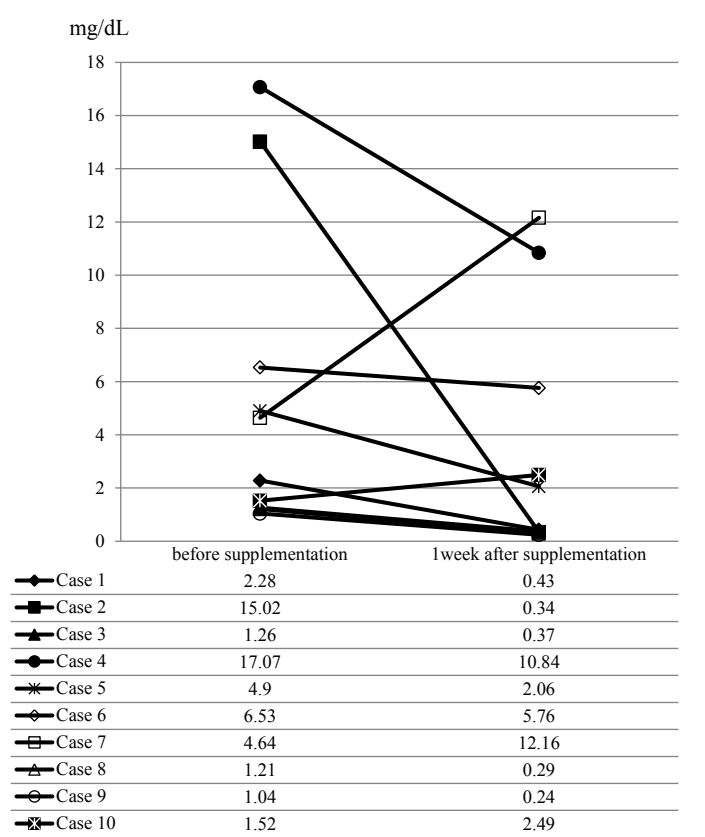

difference between the levels of CRP before and after was not observed (median CRP before supplementation, $3.46 \mathrm{mg} / \mathrm{dL}$; median CRP after supplementation, $1.25 \mathrm{mg} / \mathrm{dL}$; Wilcoxon Signed-Rank Test: $\mathrm{P}=0.160$ ). The levels of resolvin D1 after 1 week supplementation were increased in 8 patients compared with that before supplementation (Figure 5b). Seven of those eight patients showed the decreased CRP levels during supplementation. However, the significant difference between the levels of resolving D1 between before and after supplementation was not observed (median resolvin D1 before supplementation, $4431 \mu \mathrm{g} /$ $\mathrm{ml}$; median CRP after supplementation, $5830 \mu \mathrm{g} / \mathrm{ml}$; Wilcoxon SignedRank test: $\mathrm{P}=0.193)$.

\section{Discussion}

This study demonstrated that serum resolvin D1 level was significantly decreased in colorectal cancer patients with systemic inflammatory response and DHA-enriched supplement had a potential for improvement of systemic inflammatory response in colorectal cancer patients by increasing serum resolvin D1 level.

A subgroup of omega-3 FAs, primarily EPA and DHA, are essential FAs which have long been known to be important for metabolic dysfunction. Resolvins are a family of novel autacoids enzymatically generated within resolving inflammatory exudates and are biosynthesized from precursor essential omega-3 FAs, such as EPA, and DHA [21]. They are linked with a range of diseases including inflammatory disorders [22,23]. Resolvins are a new area of investigation that may aid in resolution of inflammation in various disorders. Colorectal cancer patients with a systemic inflammatory responses involving elevated CRP have been shown to have worse prognosis than those without [4-6]. Correlation between elevated CRP and resolvins has not been analyzed to our knowledge. Interestingly, this study demonstrated that patients with elevated CRP levels had significantly lower levels of resolvin D1 than those without or healthy population. The results suggested that resolvin D1 might play a key role resolving the systemic inflammation associated with cancer.

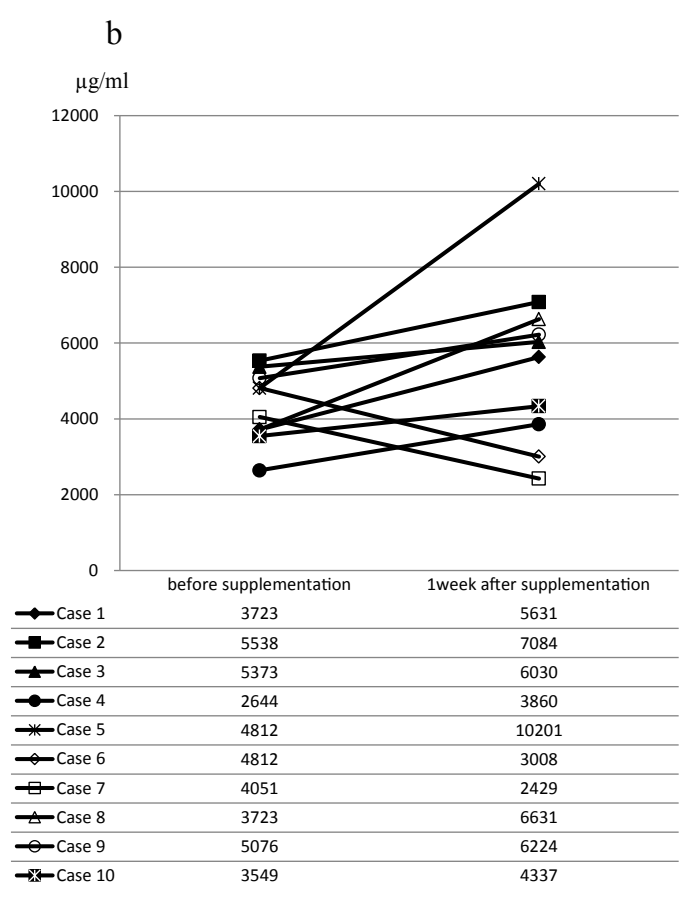

Figure 5. The serum levels of C-reactive protein and resolvin D1 before and after DHA-enriched supplementation a, serum levels of C-reactive protein; b, serum levels of resolvin D1 
Omega-3 FAs have also been shown to inhibit cell growth of several malignant cancer cells. Habermann et al. found that DHA was the most cytotoxic among the FAs including EPA [24]. This is in agreement with our in vitro findings that DHA was more efficient than EPA in suppressing cell survival in HT29 cells, possibly due to a better intracellular absorption rate of DHA than EPA in colorectal cell lines.

It is well established that the interleukin (IL)-1-IL-6 network stimulates the acute phase expression of CRP, while interaction of CRP with $\mathrm{Fc}$ receptors leads to the generation of proinflammatory cytokines that enhance the inflammatory response [25]. The IL-6-IL-6 receptor autocrine loop was previously found to exist in colorectal carcinoma, creating a local environment more favorable to tumor growth [26, 27]. The biological effect of IL- $1 \beta$ closely parallels several of the experimental features of IL-6-induced cell growth, since IL- $1 \beta$ induces IL-6 in an autocrine manner. Moreover, the presence of an acute phase reactant, such as elevated CRP, results in the tumor microenvironment being suitable for survival of colorectal cancer cells by up-regulating the local IL-1-IL-6 network system [9]. It has been unclear whether or not DHA had the potential of reducing IL-6 production from cancer cells. Recently, new mediators such as resolvin and protectins, which are involved in the resolution stage of inflammation, were found and those were products of DHA and EPA. There were few reports whether DHA inhibit the production of IL- 6 from colorectal cancer cells. Interestingly, our study demonstrated that DHA had the potential of IL-6 reduction from colorectal tumor cells.

The results from omega-3 FAs supplementation in humans have generally showed improvement in therapeutic outcome with fewer risks and side effects for patients [28-30]. Therefore, DHA and/or EPA can be administered in combination with chemotherapy or radiotherapy with a potential beneficial effect. Bougnoux et al. have revealed the presence of clinical benefit of DHA in breast cancer patients under chemotherapy [31]. This tumor progression inhibition and survival prolongation was correlated with the level of DHA absorbed to plasma. From our results of in vitro studies and previous clinical study, we hypothesized that DHA-enriched omega-3 free FAs could potentially improve the systemic inflammatory response such as elevated CRP.

To conduct supplementing study in human settings, there were two issues: the optimal dose and optimal duration of omega-3 free FAs. From previous studies, the dose of combination of EPA and DHA typically in the form of fish oil ranged from $600 \mathrm{mg}$ to $3.6 \mathrm{~g}$ per day, with different ratios of EPA to DHA. Based on clinical benefit, the optimal and safe dose established for $\mathrm{n}-3$ long chain PUFA (EPA and/ or DHA) is approximately $2 \mathrm{~g} /$ day $[29,32,33]$. The time period for the duration of supplementation ranged from 1 to 12 weeks in previous studies. Therefore, the DHA-enriched supplement $(2.2 \mathrm{~g} / \mathrm{day}$, one week supplementation) was used in clinical setting. The duration of supplementation in our study was set at one week, because our aim was to evaluate the impact of DHA-enriched supplement on systemic inflammatory response, and serum level of CRP had a short half-life (6 to 8 hours).

Lower levels of systemic inflammation, based on CRP levels, after omega-3 FAs supplementation have been observed in several studies [30,32,35-37]. These previous studies confirm the anti-inflammatory activity of fish oil FAs, and further indicate that this supplement may benefit oncologic patients. Although some studies demonstrated that omega-3 FAs help in the management of persistent chronic inflammatory states, the subjects enrolled were both patients with systemic inflammatory response and without. For this reason, the effects of omega-3 FAs on systemic inflammatory response were not fully understood. Although the significant difference was not observed between the levels of CRP before and after supplementation in our study, DHA-enriched supplement could improve the systemic inflammatory response in most colorectal patients. To confirm this finding, large scale prospective study is required in future.

In conclusion, the DHA-enriched supplement for individuals with colorectal cancer had the ability to ameliorate systemic inflammatory response which could have been worsened due to a reduced serum level of resolvin D1. This supplementation represents adjuvant in the treatment of colorectal cancer accompanied with systemic inflammatory response.

\section{References}

1. Torre LA, Bray F, Siegel RL, Ferlay J, Lortet-Tieulent J, et al. (2015) Global cancer statistics, 2012. CA Cancer J Clin 65: 87-108. [Crossref]

2. Mantovani A, Allavena P, Sica A, Balkwill F (2008) Cancer-related inflammation. Nature 454: 436-444. [Crossref]

3. Hansson GK, Robertson AK, Söderberg-Nauclér C (2006) Inflammation and atherosclerosis. Annu Rev Pathol 1: 297-329. [Crossref]

4. Proctor MJ, Morrison DS, Talwar D, Balmer SM, Fletcher CD, et al. (2011) A comparison of inflammation-based prognostic scores in patients with cancer. A Glasgow Inflammation Outcome Study. Eur J Cancer 47: 2633-2641. [Crossref]

5. Koike Y, Miki C, Okugawa Y, Yokoe T, Toiyama Y, et al. (2008) Preoperative C-reactive protein as a prognostic and therapeutic marker for colorectal cancer. J Surg Oncol 98: 540-544. [Crossref]

6. Inoue Y, Iwata T, Okugawa Y, Kawamoto A, Hiro J, et al. (2013) Prognostic significance of a systemic inflammatory response in patients undergoing multimodality therapy for advanced colorectal cancer. Oncology 84: 100-107. [Crossref]

7. Hatada T, Miki C (2000) Nutritional status and postoperative cytokine response in colorectal cancer patients. Cytokine 12: 1331-1336. [Crossref]

8. Wakuda R, Miki C, Kusunoki M (2001) Autoreactivity against interleukin 6 as a risk factor in elderly patients with colorectal carcinoma. Arch Surg 136: 1274-1279. [Crossref]

9. Miki C, Konishi N, Ojima E, Hatada T, Inoue Y, Kusunoki M (2004) C-reactive protein as a prognostic variable that reflects uncontrolled up-regulation of the IL-1-IL-6 network system in colorectal carcinoma. Dig Dis Sci 49: 970-976. [Crossref]

10. Tai CC, Ding ST (2010) N-3 polyunsaturated fatty acids regulate lipid metabolism through several inflammation mediators: mechanisms and implications for obesity prevention. J Nutr Biochem 21: 357-363. [Crossref]

11. MacLean CH, Newberry SJ, Mojica WA, Khanna P, Issa AM, et al. (2006) Effects of omega-3 fatty acids on cancer risk: a systematic review. JAMA 295: 403-415. [Crossref]

12. Terry P, Lichtenstein P, Feychting M, Ahlbom A, Wolk A (2001) Fatty fish consumption and risk of prostate cancer. Lancet 357: 1764-1766. [Crossref]

13. Hooper L, Thompson RL, Harrison RA, Summerbell CD, Ness AR, et al. (2006) Risks and benefits of omega 3 fats for mortality, cardiovascular disease, and cancer: systematic review. BMJ 332: 752-760. [Crossref]

14. Rose DP, Connolly JM (1999) Omega-3 fatty acids as cancer chemopreventive agents. Pharmacol Ther 83: 217-244. [Crossref]

15. Larsson SC, Kumlin M, Ingelman-Sundberg M, Wolk A (2004) Dietary long-chain n-3 fatty acids for the prevention of cancer: a review of potential mechanisms. Am J Clin Nutr 79: 935-945. [Crossref]

16. Serhan CN, Hong S, Gronert K, Colgan SP, Devchand PR, et al. (2002) Resolvins: a family of bioactive products of omega-3 fatty acid transformation circuits initiated by aspirin treatment that counter proinflammation signals. J Exp Med 196:1025-1037. [Crossref]

17. Campbell EL, Louis NA, Tomassetti SE, Canny GO, Arita M, et al. (2007) Resolvin E1 promotes mucosal surface clearance of neutrophils: a new paradigm for inflammatory resolution. FASEB J 21: 3162-3170. [Crossref]

18. Fredman G, Serhan CN (2011) Specialized proresolving mediator targets for RvE1 and RvD1 in peripheral blood and mechanisms of resolution. Biochem J 437: 185-197. [Crossref] 
19. Sawada Y, Honda T, Hanakawa S, Nakamizo S, Murata T, et al. (2015) Resolvin E1 inhibits dendritic cell migration in the skin and attenuates contact hypersensitivity responses. J Exp Med 212: 1921-1930. [Crossref]

20. Chan AT, Fleming CR, O'Fallon WM, Huizenga KA (1986) Estimated versus measured basal energy requirements in patients with Crohn's disease. Gastroenterology 91: 7578. [Crossref]

21. Serhan CN (2007) Resolution phase of inflammation: novel endogenous antiinflammatory and proresolving lipid mediators and pathways. Annu Rev Immunol 25: 101-137. [Crossref]

22. Monk JM, Turk HF, Fan YY, Callaway E, Weeks B, et al. (2014) Antagonizing arachidonic acid-derived eicosanoids reduces inflammatory $\mathrm{Th} 17$ and Th1 cell-mediated inflammation and colitis severity. Mediators Inflamm 2014: 917149. [Crossref]

23. Martin CR, Blanco PG, Keach JC, Petz JL, Zaman MM, Bhaskar KR, et al. (2012) The safety and efficacy of oral docosahexaenoic acid supplementation for the treatment of primary sclerosing cholangitis - a pilot study. Aliment Pharmacol Ther 35: 255-265. [Crossref]

24. Habermann N, Christian B, Luckas B, Pool-Zobel BL, Lund EK, et al. (2009) Effects of fatty acids on metabolism and cell growth of human colon cell lines of different transformation state. Biofactors 35: 460-467. [Crossref]

25. Du Clos TW (2000) Function of C-reactive protein. Ann Med 32: 274-278. [Crossref]

26. Kinoshita T, Ito H, Miki C (1999) Serum interleukin-6 level reflects tumor proliferative activity in colorectal cancer patients. Cancer $85: 2526-2531$.

27. Miki C, Tonouchi H, Wakuda R, Hatada T, Inoue Y, et al. (2002) Intra-tumoral interleukin-6 downregulation system and genetic mutations of tumor suppressor genes in colorectal carcinoma. Cancer 94: 1584-1592.

28. Laviano A, Rianda S, Molfino A, Rossi Fanelli F (2013) Omega-3 fatty acids in cancer. Curr Opin Clin Nutr Metab Care 16: 156-161. [Crossref]
29. Hajjaji N, Bougnoux P (2013) Selective sensitization of tumors to chemotherapy by marine-derived lipids: a review. Cancer Treat Rev 39: 473-488. [Crossref]

30. Granci V, Cai F, Lecumberri E, Clerc A, Dupertuis YM, et al. (2013) Colon cancer cell chemosensitisation by fish oil emulsion involves apoptotic mitochondria pathway. $\mathrm{Br} J$ Nutr 109: 1188-1195. [Crossref]

31. Bougnoux P, Hajjaji N, Ferrasson MN, Giraudeau B, Couet C, et al. (2009) Improving outcome of chemotherapy of metastatic breast cancer by docosahexaenoic acid: a phase II trial. Br J Cancer 101: 1978-1985. [Crossref]

32. Sánchez-Lara K, Turcott JG, Juárez-Hernández E, Nuñez-Valencia C, Villanueva G, et al. (2014) Effects of an oral nutritional supplement containing eicosapentaenoic acid on nutritional and clinical outcomes in patients with advanced non-small cell lung cancer: randomised trial. Clin Nutr 33: 1017-1023. [Crossref]

33. Murphy RA, Mourtzakis M, Mazurak VC (2012) n-3 polyunsaturated fatty acids: the potential role for supplementation in cancer. Curr Opin Clin Nutr Metab Care 15: 246251. [Crossref]

34. Silva Jde A, Trindade EB, Fabre ME, Menegotto VM, Gevaerd S, et al. (2012) Fish oi supplement alters markers of inflammatory and nutritional status in colorectal cancer patients. Nutr Cancer 64: 267-273. [Crossref]

35. Mocellin MC, Pastore e Silva Jde A, Camargo Cde Q, Fabre ME, Gevaerd S, et al (2013) Fish oil decreases C-reactive protein/albumin ratio improving nutritional prognosis and plasma fatty acid profile in colorectal cancer patients. Lipids 48: 879888. [Crossref]

36. Finocchiaro C, Segre O, Fadda M, Monge T, Scigliano M, et al. (2012) Effect of n-3 fatty acids on patients with advanced lung cancer: a double-blind, placebo-controlled study. Br J Nutr 108: 327-333. [Crossref]

37. van der Meij BS, Langius JA, Smit EF, Spreeuwenberg MD, von Blomberg BM, et al. (2010) Oral nutritional supplements containing (n-3) polyunsaturated fatty acid affect the nutritional status of patients with stage III non-small cell lung cancer during multimodality treatment. $J$ Nutr 140: 1774-1780. [Crossref]

Copyright: (C2016 Mohri Y. This is an open-access article distributed under the terms of the Creative Commons Attribution License, which permits unrestricted use, distribution, and reproduction in any medium, provided the original author and source are credited. 